\title{
Embryonic and Morphological Development of Larvae and Juvenile of the Buenos Aires Tetra, Hyphessobrycon anisitsi (Pisces Characidae) Characidae Fishes
}

\author{
Jae-Min Park ${ }^{1}$, Kyeong-Ho Han ${ }^{2}$ and ${ }^{\dagger}$ Ran Han $^{3}$ \\ ${ }^{1}$ Gyeongsangbuk-do Native Fish Business Center, Uiseong 769-921, Korea \\ ${ }^{2}$ Dept. of Aqualife Science, Chonnam National University, Yeosu 550-749, Korea \\ ${ }^{3}$ Lotteworld Aquarium, Seoul 138-240, Korea
}

\begin{abstract}
We have launched an investigation for Embryonic Development, Larvae and Juvenile Morphology, of Buenos aires tetra in order to build basic data of Characidae and fish seeding production. We brought 50 couples of Characidae from Bizidduck aquarium in Yeosu-si, Jeollanamdo, from Korea on March of 2015. We put them in the tetragonal glass aquarium $(50 \times 50 \times 30 \mathrm{~cm})$. Breeding water temperature was $27.5 \sim 28.5^{\circ} \mathrm{C}$ (mean $\left.28.0 \pm 0.05^{\circ} \mathrm{C}\right)$ and being maintained. The shape of fertilized egg was round shape, and it was adhesive demersal egg. The egg size was 0.63 0.91 mm (mean $0.74 \pm 0.07 \mathrm{~mm}$, $\mathrm{n}=20$ ). After getting fertilized egg, the developmental stage was gastrula stage, and embryo covered almost two-thirds of Yolk. Incubation was happened after 16 hours 13 minutes from gastrula stage, and the tail of juvenile came out first with tearing egg capsule. Immediately after the incubation, prelarvae had $3.78 \sim 3.88 \mathrm{~mm}$ length (mean $3.84 \pm 0.04 \mathrm{~mm}, \mathrm{n}=5$ ), and it had no mouth and anus yet. 34 days after hatching from the incubation, juvenile had $8.63 \sim 13.1 \mathrm{~mm}$ (mean $10.9 \pm 1.66 \mathrm{~mm}$ ), and it had similar silver-colored body shape with its mother.
\end{abstract}

Key words : Buenos aires tetra, Embryonic development, Hyphessobrycon anisitsi, Juvenile, Larvae

\section{INTRODUCTION}

Buenos aires tetra (Hyphessobrycon anisitsi) is fresh water teleost of Characiformes Characidae, and is distributed throughout Brazil, Argentina, and Paraguay in South America. Its body length is $5 \sim 7 \mathrm{~cm}$, and its lifespan is about $5 \sim 7$ years. Characteristically the entire body is silver and the caudal fins are reddish.

Studies which is realated to made on Characidae in Korea include those on the fertilized eggs of Hemigrammus ocellifer, Gymnocorymbus ternetzi, and H. caudovittatus (Kim et al.,
1996) and of $H$. serpae (Kim et al., 2005), and on the microstructure of egg membrane (Lee et al., 2008).

In other countries, antioxidant defense capacity against ammonia stress (Pan et al., 2011), the early development of skull (Vandewalle et al., 2005), embryo development (Nakaghi et al., 2013; Weber et al., 2012), etc. have been studied.

Characidae fish like Buenos aires tetra is easy for mass seed production, and because it is cheaper than other tropical fish, it is sold actively as feed for large carnivorous fish. Most of its demand from Korean consumers is supplied through import, and there are only a few producers in

\footnotetext{
Manuscript received 20 January 2015, Received in revised form 5 February 2015, Accepted 17 February 2015

${ }^{\dagger}$ Corresponding Author : Ran Han, Lotteworld Aquarium, Seoul, 138-240, Korea. Tel : +82-2-3213-3284, Fax : +82-2-3213-3250, E-mail : gost016803 @ naver.com

This is an Open Access article distributed under the terms of the Creative Commons Attribution Non-Commercial License (http:// creativecommons.org/licenses/by-nc/3.0) which permits unrestricted non-commercial use, distribution, and reproduction in any medium, provided the original work is properly cited.
} 
Korea. In this situation, more research and technology for seed production are required. Thus, this study investigated the egg development of Buenos aires tetra and the morphological development of larvae and juveniles in order to provide basic information for the seed production of Characidae fish.

\section{MATERIALS AND METHODS}

\section{Broodstock rearing}

In May 2012, 50 mature mothers $5.55 \sim 7.32 \mathrm{~cm}$ in full length (mean $6.44 \pm 1.25 \mathrm{~cm}$; Fig. 1) were purchased from Bizidduck Aquarium in Yeosu, Jollanam-do, and put in a rectangular glass water tank $(50 \times 50 \times 30 \mathrm{~cm})$. In the water, $\mathrm{pH}$ was maintained at 6.00 6.50 (mean 6.25 \pm 0.02 ), and dissolved oxygen concentration at 5.94 7.10 mg/L (mean $6.73 \pm 0.29 \mathrm{mg} / \mathrm{L}$ ). Breeding water temperature was maintained at $27.5 \sim 28.5^{\circ} \mathrm{C}$ (mean $28.0 \pm 0.05^{\circ} \mathrm{C}$ ) using an electric heater (Warmton 50w, Korea), and clean water was maintained by removing waste and feed leftover accumulated on the floor of the tank using sponge filter (SF-2822, Korea). The fish were fed twice a day (AM 8:00; FM 17:00), and frozen blood worms (Hikari, Japan) and formula feed (Love Larva, Japan) were used.

\section{Embryonic development and the morphological} development of larvae and juveniles

Fertilized eggs were put in a $500 \mathrm{~mL}$ glass beaker, and breeding water temperature was maintained within the range of $26.5 \sim 27.5^{\circ} \mathrm{C}$ (mean $27.0 \pm 0.05^{\circ} \mathrm{C}$ ) until hatching. Half of the breeding water was changed three times a day, and egg size was measured up to $0.01 \mathrm{~mm}$ using a profile projector (Nikon JP V-12B, Japan) with 20 individuals sampled at random, and the process of egg development was observed and photographed under a stereoscopic microscope (Nikon JP SMZ800, Japan).

Larvae just after hatching were put in a rectangular glass

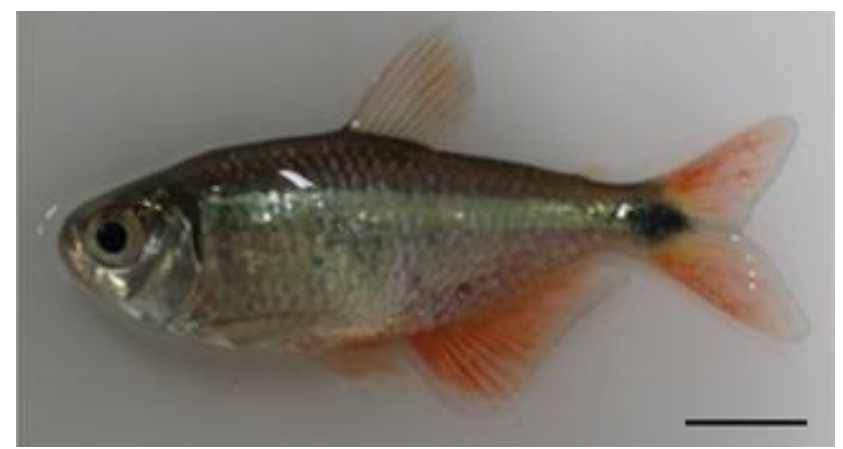

Fig. 1. Lateral view of buenos aires tetra, Hyphessobrycon anisitsi. Scale bar $=1.0 \mathrm{~cm}$.

water tank $(50 \times 50 \times 30 \mathrm{~cm})$, and bred there in stagnant water, and air was supplied weakly through aeration. As feed for larvae and juveniles, rotifer (Branchionus rotundiformis) was supplied until 7 days after hatching yolk absorption and the feeding rate was $5 \sim 10$ individuals/ $\mathrm{mL}$. Then, Brine shrimp (nauplius of Artemia sp.; Westwood premium gold) was supplied at a rate of $10 \sim 15 / \mathrm{mL}$ from Day 7 to 20, and formula feed (200 310 $\mu \mathrm{m}$; Love Larva, Japan) was supplied together from Day 20 to 30.

For the morphological obsrevation of larvae and juveniles, 5 individuals were anesthetized with anesthetic (MS-222, Ethyl 3-aminobenzoate methanesulfonate, Sigma Aldrich Co., St. Louis, USA) each day after hatching, and each region of the body was measured up to $0.01 \mathrm{~mm}$ and observed using a profile projector and a stereoscopic microscope. The morphological stages of larvae and juveniles were divided according to Rusell (1976).

\section{RESULTS}

\section{Morphology of eggs}

The form of fertilized eggs was globular without a quarter, and the color of the yolk was light red. Fertilized eggs were adhesive demersal eggs, and egg diameter was $0.63 \sim 0.91 \mathrm{~mm}$ (mean 0.74 $\pm 0.07 \mathrm{~mm}, \mathrm{n}=20$ ).

\section{Embryonic development}


The developmental stage when the fertilized eggs were collected was the mid-gastrula stage as the germinal disk covered down up to $2 / 3$ of the yolk (Fig. 2A), and the embryoid body began to be formed along the yolk in an hour 30 minutes after the gastrula stage (Fig. 2B).

In 3 hours 53 minutes after the gastrula stage, 6 myotomes were formed on the embryoid body, and the eye

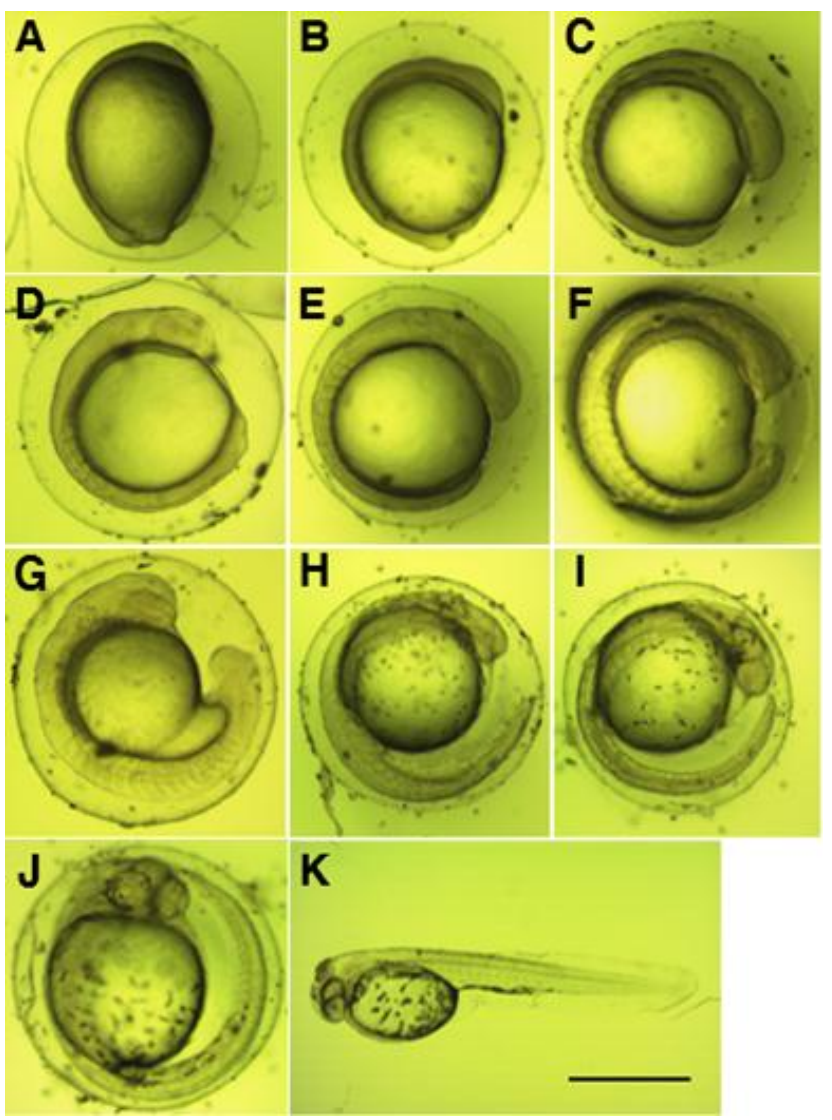

Fig. 2. The embryonic development stages of buenos aires tetra, Hyphessobrycon anisitsi. A: Gastrula stage; B: Head of embryo developing, 1 hrs 30 mins; C: 6 myotomes stage, 3 hrs 53 mins; D: 7 myotomes stage, 4 hrs 53 mins; E: Formation of eyes, 5 hrs 23 mins; F: Appearance of Kuffer's vesicles, 6 hrs 23 mins; G: 19 myotomes stage, 7 hrs 23 mins; H: Appearance of melanophores in the yolk sac, 9 hrs 23 mins; I: Otolith of developing, 10 hrs 53 mins; J: Appearance of melanophores in the tail, 12 hrs 13 mins; K: Hatching larvae. Scale bar $=1.0 \mathrm{~mm}$. vesicle began to be formed (Fig. 2C). In 4 hours 53 minutes after the gastrula stage, the number of myotomes on the embryoid body increased to 7 , and the tail began to develop (Fig. 2D). In 5 hours 23 minutes after the gastrula stage, the number of myotomes on the embryoid body increased to 9 , and the eyeball began to be formed (Fig. 2E).

In 6 hours 23 minutes after the gastrula stage, the number of myotomes on the embryoid body increased to 15 , and Kuffer's vesicle was formed on the base of the tail (Fig. 2F). In 7 hours 23 minutes after the gastrula stage, the number of myotomes on the embryoid body increased to 19 , the tail began to be separated from the yolk, and Kuffer's vesicle formed on the base disappeared (Fig. 2G). In 9 hours 23 minutes after the gastrula stage, speckle-like black vesicles were deposited on the upper part of the yolk, and membrane was formed on the caudal fins and developed long (Fig. 2H).

In 10 hours 53 minutes after the gastrula stage, the caudal fin extended up to the tip of the head, and the otolith developed (Fig. 2I). In 12 hours 13 minutes after the gastrula stage, black vesicles were deposited around the eyes and on the base of the tail (Fig. 2J), and in 16 hours 13 minutes after the gastrula stage, hatching through the egg membrane was started, beginning with the tail (Fig. 2K).

\section{Morphological development of larvae and juveniles}

Fig. 4 shows the growth of larvae and juveniles. Prelarvae just after hatching were $3.78 \sim 3.88 \mathrm{~mm}$ in full length (mean $3.84 \pm 0.04 \mathrm{~mm}, \mathrm{n}=5$ ) and had membranous fins from the back at the center of the body to the end of the yolk, and the mouth and the anal were not opened. Black vesicles were deposited around the eyes, on the upper part of the yolk, and on the bottom of the trunk (Fig. 3A). Prelarvae on the 2 days after hatching were 4.01 4.24 $\mathrm{mm}$ in full length (mean $4.11 \pm 0.09 \mathrm{~mm}$ ), and branch-like black vesicles were deposited on the upper part of the head, on the back, and on the base of the tail (Fig. 3B). Post-larvae 
on the 7 days after hatching were $4.11 \sim 4.58 \mathrm{~mm}$ in full length (mean $4.28 \pm 0.23 \mathrm{~mm}$ ), their mouth and anal were opened, and the yolk was absorbed completely. As the swim bladder was formed inside, they began to swim, and fan-shaped caudal fins began to develop (Fig. 3C). Postlarvae on the 11 days after hatching were 5.30 6.13 $\mathrm{mm}$ in full length (mean $5.74 \pm 0.31 \mathrm{~mm}$ ), and as their jaw developed, they began to eat feed actively. In addition, black vesicles were deposited on the upper part of the gill openings. Rays began to develop at the end of the caudal fins, and round pectoral fins developed (Fig. 3D). Postlarvae on the 20 days after hatching were 5.94 7.15 $\mathrm{mm}$ in full length (mean $6.45 \pm 0.61 \mathrm{~mm}$ ), and the number of fin rays formed was 5 in the dorsal fin, 11 in the anal fin, and 17 in the caudal fin. Speckle-like black vesicles were deposited at the center of the caudal fins (Fig. 3E). Postlarvae on the 24 days after hatching were $6.15 \sim 7.25 \mathrm{~mm}$ in full length (mean 6.76 $\pm 0.52 \mathrm{~mm}$ ), and their dorsal, anal, and caudal fins connected through membrane were separated. The ventral fins were separated but were still membranous. At this stage, the number of fin rays increased to 10 in the dorsal fin, to 14 in the anal fin, and to 20 in the caudal fin. Speckle-like black vesicles were deposited also on the dorsal and anal fins (Fig. 3F). Juveniles on the 28 days after hatching were $6.53 \sim 8.42 \mathrm{~mm}$ in full length (mean $7.77 \pm 1.59 \mathrm{~mm}$ ), and the number of fin rays increased to 11 in the dorsal fin, to 25 in the anal fin, and to 22 in the caudal fin. In addition, the caudal fins developed into the form of homocercal fin. The black vesicles deposited at the center of the caudal fins developed into large speckles (Fig. 3G).

Juveniles on the 34 days after hatching were 8.63 13.1 $\mathrm{mm}$ in full length (mean 10.9 $\pm 1.66 \mathrm{~mm}$ ). Rays were formed in the membranous ventral fins, and the adipose fin was formed on the upper part of the caudal peduncle. The lower jaw developed longer than the upper jaw, and as the color turned silver their overall shape became similar to the mother's (Fig. 3H).

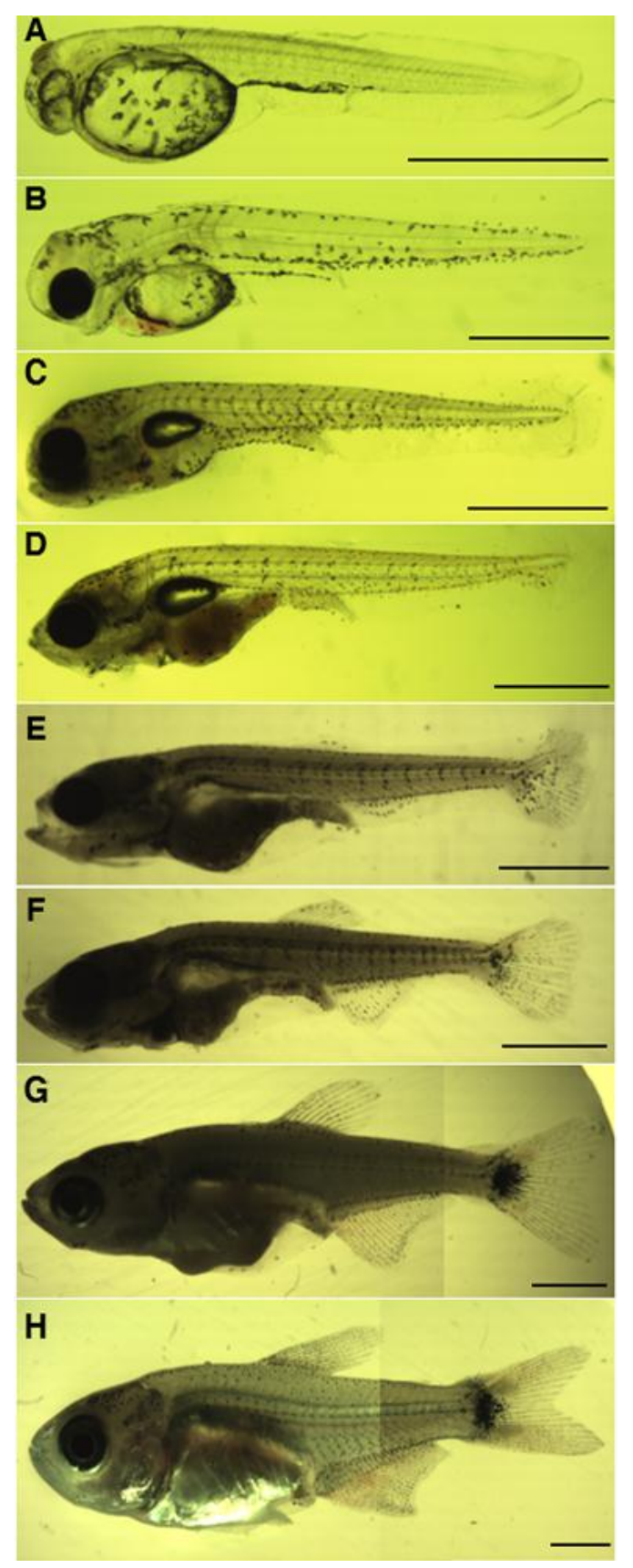

Fig. 3. Morphological development of the larvae and juvenile of buenos aires tetra, Hyphessobrycon anisitsi. A: $3.84 \mathrm{~mm}$ in total length (TL) newly hatched larvae; B: $4.11 \mathrm{~mm}$ in TL, 2 days after hatching; C: $4.28 \mathrm{~mm}$ in TL, 7 days after hatching; D: $5.74 \mathrm{~mm}$ in TL, 11 days after hatching; E: 6.45 $\mathrm{mm}$ in TL, 20 days after hatching; F: $6.76 \mathrm{~mm}$ in TL, 24 days after hatching; G: $7.77 \mathrm{~mm}$ in TL, 28 days after hatching; $\mathrm{H}$ : $10.9 \mathrm{~mm}$ in TL, 34 days after hatching. Scale bars $=1.0 \mathrm{~mm}$. 


\section{DISCUSSION}

The Amazon River in South America inhabited by Buenos aires tetra has several tributaries along with the main stream and therefore it teems with a large diversity of tropical fish species. However, tropical fish resources are shrinking rapidly due to recent development of primary forest areas, droughts caused by extreme weather events, indiscreet over fishing, etc. As environmental conditions for producing various kinds of tropical fish are growing worse, it is urgently necessary to make research on the reproduction and preservation of species.

Buenos aires tetra has one adipose fin on the upper part of the caudal peduncle, and such a fin is also observed in Serpae tetra, Hyphessobrycon eques (Park et al., 2014), Black skirt tetra, Gymnocorymbus ternetzi (Ihsan et al., 2012), etc.

Buenos aires tetra swims along the current of water, but it repeats staying in stagnant water and then swimming. At that time, the adipose fin is believed to play an important role in balancing the body while swimming in the water.

The fertilized eggs of Buenos aires tetra were globular without a quarter, and were adhesive demersal eggs. Egg diameter was 0.63 0.91 mm (mean 0.74 $\pm 0.07 \mathrm{~mm}$ ), larger than that of Tiger fish and Hydrocynus vittatus (Steyn et al., 1996) and smaller than $0.92 \mathrm{~mm}$ of Serpae tetra (Park et al., 2014), $1.13 \mathrm{~mm}$ of Brycon gouldingi (Faustino et al., 2011), and 1.49 3.09 mm of B. orthotaenia (Gomes et al., 2011) among other fish of the same family.

In the results of comparing time taken until hatching, it took 16 hours 13 minutes after the gastrula stage at mean water temperature $27.0 \pm 0.05^{\circ} \mathrm{C}$ in Buenos aires tetra, 12 hours at $28.0 \pm 0.05^{\circ} \mathrm{C}$ in Serpae tetra, 22 hours 30 minutes at $28.0 \pm 1{ }^{\circ} \mathrm{C}$ in Tiger fish (Steyn et al., 1996), 13 hours at $26.4 \pm 1.12^{\circ} \mathrm{C}$ in B. gouldingi (Faustino et al., 2011), 28 hours 20 minutes at $21^{\circ} \mathrm{C}$ in Bryconamericus caucanus (Montoya et al., 2010), 21 hours 30 minutes at $24^{\circ} \mathrm{C}$ in $B$. orthotaenia (Gomes et al., 2011), and 20 21 hours at
24.0 $\pm 0.5^{\circ} \mathrm{C}$ in Black skirt tetra (Ihsan et al., 2012). Characidae fish tended to develop slow at low breeding water temperature, and fast at high breeding water temperature (Byun et al., 2009).

As to the size of larvae just after hatching, the full

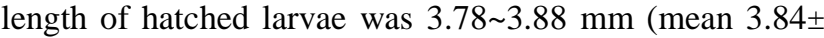
$0.04 \mathrm{~mm}$ ) in Buenos aires tetra, 2.76 3.05 mm (mean $2.89 \pm 0.16 \mathrm{~mm}$ ) in Serpae tetra (Park et al., 2014), $2.87 \pm$ $0.15 \mathrm{~mm}$ in B. orthotaenia (Gomes et al., 2011), $2.90 \mathrm{~mm}$ in Tiger fish (Steyn et al., 1996), and $1.44 \pm 14.3 \mathrm{~mm}$ in Black skirt tetra (Ihsan et al., 2012), so Buenos aires tetra showed the largest larva size.

As to the time for transition to the juvenile stage and size at that time, it was the $34^{\text {th }}$ day from hatching and the full length was $8.63 \sim 13.1 \mathrm{~mm}$ (mean $10.9 \pm 1.66 \mathrm{~mm}$ ) in Buenos aires tetra, and the 45 days and 11.9 14.1 mm (mean 12.5 $\pm 1.60 \mathrm{~mm}$ ) in Serpae tetra (Park et al., 2014) (Table 1). The process of early development and the morphological development of larvae and juveniles are very important data not only for the identification of species but also for the preservation of endangered species (Seo et al., 2010). In order to preserve the number of Characidae fish against overfishing, we must find good solutions with ecological research on broodstock rearing, life, environment and so on.

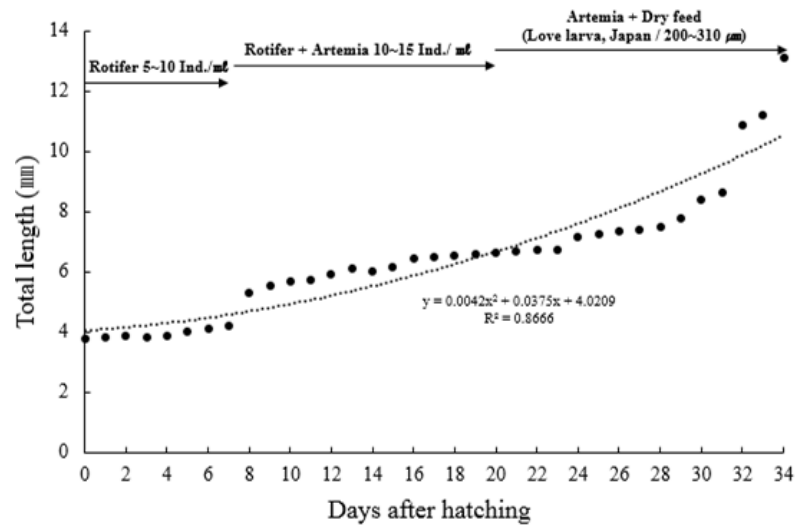

Fig. 4. Early growth of buenos aires tetra, Hyphessobrycon anisitsi larvae and juvenile after hatching. 
J-M Park, K-H Han, R Han

Table 1. Comparison of egg and larvae characteristics in Characidae fishes

\begin{tabular}{cccccc}
\hline \hline Species & Egg diameter $(\mathrm{mm})$ & $\begin{array}{c}\text { Time of } \\
\text { hatching }(* \mathrm{WT})\end{array}$ & $\begin{array}{c}\text { Hatching } \\
\text { larvae size }(\mathrm{mm})\end{array}$ & $\begin{array}{c}\text { Juvenile } \\
(\mathrm{mm})\end{array}$ & Reference \\
\hline $\begin{array}{c}\text { Hyphessobrycon } \\
\text { anisitsi }\end{array}$ & $\begin{array}{c}0.74 \pm 0.07 \\
(0.63-0.91)\end{array}$ & $\begin{array}{c}16 \mathrm{hrs} 13 \mathrm{mins} \\
\left(27.0 \pm 0.05^{\circ} \mathrm{C}\right)\end{array}$ & $\begin{array}{c}3.84 \pm 0.04 \\
(3.78-3.88)\end{array}$ & $\begin{array}{c}10.9 \pm 1.66 \\
(8.63-13.1)\end{array}$ & Present study \\
\hline $\begin{array}{c}\text { Hyphessobrycon } \\
\text { eques }\end{array}$ & $\begin{array}{c}0.92 \pm 0.01 \\
(0.91-0.93)\end{array}$ & $\begin{array}{c}12 \mathrm{hrs} \\
\left(28.0 \pm 0.05^{\circ} \mathrm{C}\right)\end{array}$ & $\begin{array}{c}2.89 \pm 0.16 \\
(2.76-3.05)\end{array}$ & $\begin{array}{c}12.5 \pm 1.60 \\
(11.9-14.1)\end{array}$ & Park et al., 2014 \\
\hline $\begin{array}{c}22 \mathrm{hrs} \\
\left(28.0 \pm 1^{\circ} \mathrm{C}\right)\end{array}$ & 2.90 & - & Steyn et al., 1996 \\
$\begin{array}{c}\text { Hydrocynus vittatus } \\
\text { Bouldingi }\end{array}$ & 0.65 & $\begin{array}{c}13 \mathrm{hrs} \\
\left(26.4 \pm 1.12^{\circ} \mathrm{C}\right)\end{array}$ & - & - & Faustino et al., 2011 \\
\hline $\begin{array}{c}\text { Brycon orthotaenia } \\
\text { Bryconamericus } \\
\text { caucanus }\end{array}$ & $1.49-3.09$ & $\begin{array}{c}21 \mathrm{hrs} 30 \mathrm{mins} \\
\left(24.0^{\circ} \mathrm{C}\right)\end{array}$ & $2.87 \pm 0.15$ & - & Gomes et al., 2011 \\
\hline $\begin{array}{c}\text { Gymnocorymbus } \\
\text { ternetzi }\end{array}$ & - & $\begin{array}{c}28 \mathrm{hrs} 20 \mathrm{mins} \\
\left(21.0^{\circ} \mathrm{C}\right)\end{array}$ & - & - & Montoya et al., 2010 \\
\hline
\end{tabular}

*WT: water temperature

\section{REFERENCES}

Byun SG, Lee SH, Hwang JH, Han KH, Kang KW, Kim JD, Kim YC, Lee BI (2009) Embryonic and larva development of slime flounder, Microstomus achne. Dev Reprod 13:281-289.

Faustino F, Nakaghi LS, Neumann E (2011) Brycon gouldingi (Teleostei, Characidae): aspects of the embryonic development in a new fish species with aquaculture potential. Zygote 19:351-363.

Gomes RZ, Sato Y, Rizzo E, Bazzoli N (2011) Early development of Brycon orthotaenia (Pisces: Characidae). Zygote 21:11-20.

Ihsan C, Pmar C, Sukran C, Mert G, Sibel H (2012) Embryonic and larval development of black skirt tetra (Gymnocorymbus ternetzi, Boulenger, 1895) under laboratory conditions. Aquaculture 43:1260-1275.

Kim DH, Deung YK, Lee KJ (2005) Ultrastructure of the fertilized egg envelope from Hyphessobrycon serpae, characidae, teleost. Korean J Elec Micro 35:89-96.
Kim DH, Reu DS, Deung YK (1996) A comparative study on the ultrastructures of the egg envelope in fertilized egg of fishes, characidae, three species. Korean J Elec Micro 26:277-291.

Lee KJ, Jang BS, Teng YC, Kim DH (2008) The oogenesis of glow-light tetra, characidae, teleost. Korean J Micro 38:315-319.

Montoya A, Arias M, Olivera-Angel M (2010) Embryonic development of Bryconamericus caucanus (Characidae: Tetragonpterinae) under laboratory conditions. Int $\mathbf{J}$ of Mor 28:869-872.

Nakaghi LS, Neumann E, Faustino F, Mendes JM, Braga FM (2013) Moments of induced spawning and embryonic development of Brycon amazonicus (Teleostei, Characidae). Zygote First View Article:1-9.

Pan CH, Chien YH, Wang YJ (2011) Antioxidant defence to ammonia stress of characins (Hyphessobrycon eques Steindachner) fed diets supplemented with carotenoids. Aquaculture Nutrit 17:258-266.

Park JM, Kim NR, Han KH, Han JH, Son MH, Cho JK 
(2014) Spawning behavior, egg development, larvae and juvenile morphology of Hyphessobrycon eques (Pisces: Characidae) characidae fishes. Dev Repord 18: 241-249.

Rusell FS (1976) The Eggs and Planktonic Stages of British

Marine Fishes. Academic Press Inc London pp. 524.

Seo WI, Yoo DJ, Byun SG, Kim YC, Lee SH, Yeon IH,

Yim HS, Lee BI (2010) Spawning behavior and early life history of endangered Cottus hangiongensis. Kor J Fish Aquat Sci 43:46-53.

Steyn GJ, Gagiano CL, Deacon AR, Preez HH (1996) Notes on the induced reproduction and development of the tiger fish, Hydrocynus vittatus (Characidae), embryos and larvae. Environ Biol of Fishes 47:387-398.

Vandewalle P, Germeau G, Besancenet P, Parmentier E, Baras E (2005) Early development of the head skeleton in Brycon moorei (Pisces: Ostariophysi, Characidae). Fish Biol 66:996-1024.

Weber AA, Arantes FP, Sato Y, Rizzo E, Bazzoli N (2012) Oocyte adhesiveness and embryonic development of Astyanax bimaculatus (Linnaeus, 1758) (Pisces: Characidae). Zygote 21:198-202. 